\title{
DC Line to line Short-Circuit Fault Management in a Turbo-Electric Aircraft Propulsion System using Su- perconducting Devices
}

\author{
Sriharsha Venuturumilli, Frederick Berg, Lucien Prisse, Min Zhang, Weijia Yuan
}

\begin{abstract}
Electric aircraft has already become a reality, with demonstration flights at power ratings of less than 1 MVA. Conventional machines and distribution technologies suffer from poor power densities when scaling to large power demands, leading to significant challenges in applying this technology from small $(<10-$ seater) to large ( $>100$-seater) planes. Superconducting devices could be an enabler for electric aviation due to their great potential for high efficiency and low weight. However, while the development of the superconducting components presents a significant challenge, the safe and effective combination of such components into a propulsion system also requires a significant area of research. For this purpose, a signal-based Matlab-Simscape model for a DC network architecture in a turbo-electric aircraft has been established and the highly nonlinear models for the superconducting devices have been developed and integrated. This network model has been used to understand the fault current magnitude and rise time, as well as the stability behavior of the system utilizing the realistic electro-thermal models of superconducting devices in it. The derived network was investigated for a bus bar short circuit fault using both superconducting fault current limiter (SFCL) and fault current limiting high temperature superconducting (FCL HTS) cable. Based on the network characteristics, a fault tolerant DC network design was achieved by utilizing the FCL HTS cables. Similarly, the operation limits of the protection devices have been reduced greatly using superconducting components.
\end{abstract}

Index Terms - Aircraft Propulsion, Fault tolerance, HTS cables, Power system faults, Short circuit currents, System engineering.

\section{INTRODUCTION}

$\mathbf{T}$ TURBO-ELECTRIC aircraft propulsion system is a novel idea [1], capable of realizing the emission standards set by the Flightpath 2050 [2]. Replacement of the conventional engines with electric propulsion motors was speculated to be the prom-

Manuscript receipt and acceptance dates will be inserted here. This work was supported by Airbus Group Innovations. (Corresponding authors: S. Venuturumilli \& $W$. Yuan)

$\mathrm{S}$. Venuturumilli, is registered with the Department of Electronics and Electrical Engineering, University of Bath, Bath BA2 7AY, U.K. and currently working as a visiting researcher at Department of Electronics and Electrical Engineering, University of Strathclyde, Glasgow - G1 1XW, U.K. (e-mail: sv370@bath.ac.uk);

F. Berg and L. Prisse are with Airbus E-Aircraft Systems, Munich, Germany (e-mail: frederick.berg@airbus.com; Lucien.prisse@airbus.com)

M. Zhang, and W. Yuan are with the Department of Electronics and Electrical Engineering, University of Strathclyde, Glasgow - G1 1XW, U.K. (min.zhang@strath.ac.uk; weijia.yuan@strath.ac.uk).

Color versions of one or more of the figures in this paper are available online at http://ieeexplore.ieee.org.

Digital Object Identifier will be inserted here upon acceptance. ising idea [3] to compete with the reduction in emission targets of $75 \% \mathrm{CO}_{2}, 90 \% \mathrm{NO}_{\mathrm{X}}$ and $65 \%$ perceived noise emission compared to those in 2000.

Several crucial components of aircraft have already been electrified, adding more control and efficiency [4,5]. But, replacement of the conventional engines with electric motors for large aircraft is still a major challenge towards realizing electric aircraft. NASA has been a pioneer and published an initial investigative study on the applicability and limitations of the existing technology for making this idea a reality [6]. One of the major challenges is the use of superconducting machines, which requires continuous flow of cryogen at a set temperature and the need for power electronics to operate at cryogenic temperature [7]. Superconducting machines were a necessity, as the existing machines can only be scaled up to certain limit with the high efficiency characteristics [8].

Based on the weight, size and efficiency, various architectures have been evaluated for the aircraft propulsion system, namely: AC, DC and Hybrid [9]. Of them, the overall efficiency of the AC architecture was evaluated to be the best, but this architecture is complicated in its control strategy [10]. On the other hand, DC and hybrid systems are straight forward, and their control strategy has already been established in these systems $[11,12]$. Hybrid system can be a good option, but suffers from AC losses, as AC superconducting cables are being used for the power transmission. DC architecture on the other hand uses the DC power transmission eliminating the AC loss problem and has been considered in the present paper.

The assumed turbo-electric DC architecture comprises of the Generator (G), Rectifier, Cables, Inverter and Propulsion Motors (M) with the appropriate protection system as shown in Fig. 1. The DC system comprises of 2 poles with the negative pole being grounded as shown in Fig. 1. In this paper, a

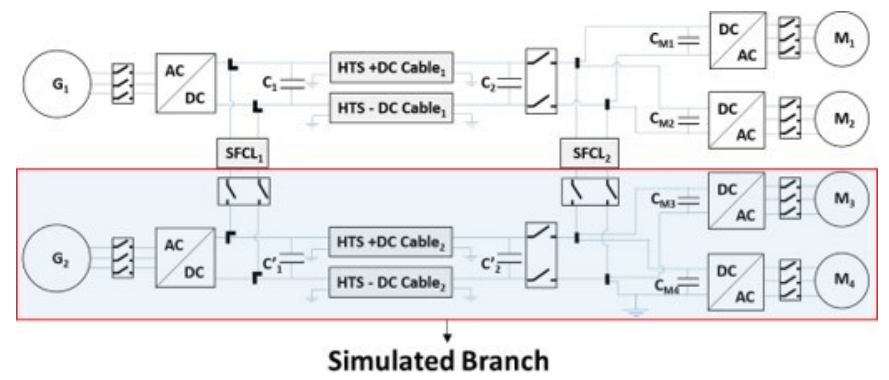

Fig. 1: Single line diagram of the proposed architecture of Turbo-Electric DC electric aircraft, where $\mathrm{G}$ stands for generator, $\mathrm{M}$ for motor. 
full-scale system model was built in the Matlab - Simscape environment and the conventional copper cables are replaced with high temperature superconducting (HTS) cables. Previously HTS cables for electric aircraft have been modelled/characterized independently [13-15]. This paper for the first time presents the use of HTS cables in the full-scale system model of the turbo-electric aircraft and studies its impact on the fault current characteristics.

Of various faults simulated, a DC rail-rail fault was observed as critical, with the peak current magnitudes reaching up to 100 times the rated current, within a duration of 10-100 microseconds [16]. The primary reason for these large current magnitudes is the DC capacitive discharge and the second one is the low resistance of the entire system being operating in the cryogenic temperatures. Using superconducting fault current limiter (SFCL) and fault current limiting (FCL) HTS cable with slight modifications within the system model, a novel fault current tolerant system model was presented in this paper. Additionally, a lumped thermo-electric model of the HTS $\mathrm{DC}$ cable with the evaluated AC loss formulae have been presented.

\section{HTS DC CABLE MODEL}

A lumped superconducting cable model was built to simulate the characteristics of the HTS DC cable that have a length of $100 \mathrm{~m}$ and ratings of $4000 \mathrm{~V}$ and $2 \mathrm{kA}$. The cable model was developed based on the cross-sectional layout of the HTS DC cable as presented in the Fig. 2. The core of the HTS cable was assumed as copper conductor to provide the required quench protection under fault current conditions. Both conduction and shield layer are assumed to be of superconducting with variable number of $4 \mathrm{~mm}$ width HTS tapes (i.e. conduction layer -20 and shield layer - 25) for reduced AC losses, but with same critical current, $I_{C}$ values.

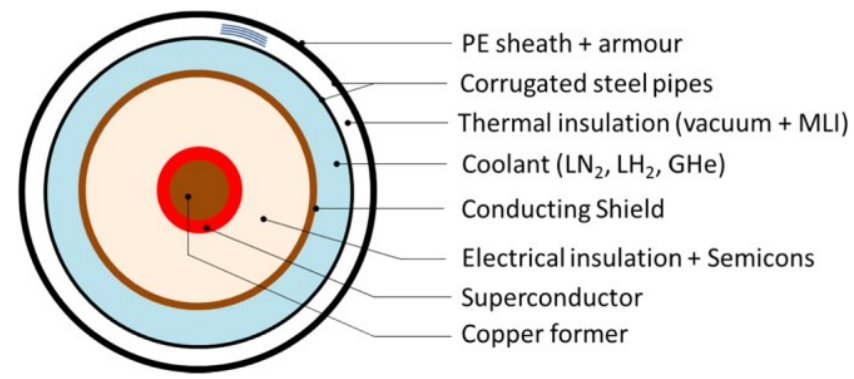

Fig. 2: Schematic layout of the HTS DC cable cross-section [17].

For simplification, the HTS tape was considered to have only the HTS layer and Copper layer, neglecting the other layers in both electrical and thermal models. The highly nonlinear property of HTS material has been modelled using the E-J power law, according to Equation (1).

$\rho_{\mathrm{HTS}}=\frac{E_{c}}{J_{c}(T)}\left(\frac{J}{J_{c}(T)}\right)^{n} T<T_{c}, J<J_{c}$

where, $\rho_{\text {HTS }}$ was the "resistivity of HTS material $(\Omega . m)$ ", $E_{C}$ being the "critical electric field $(\mathrm{V} / \mathrm{m})$ ", $\mathrm{T}_{\mathrm{C}}$ being "critical temperature $(\mathrm{K})$ ", $\mathrm{J}_{\mathrm{C}}$ being the "critical current density $\left(\mathrm{A} / \mathrm{m}^{2}\right)$ " and $\mathrm{n}$ was made equal to 20 . The critical current den- sity, $\mathrm{J}_{\mathrm{C}}$ of the HTS material varies with the operating temperature, $\mathrm{T}$ according to Equation (2).

$J_{c}(T)=J_{\mathrm{co}}\left(\frac{\left(T_{c}-T(t)\right)^{\alpha}}{\left(T_{c}-T_{o}\right)^{\alpha}}\right)$

where, ' $\alpha$ ' is set as 1.5 based on the ' $\mathrm{J}_{\mathrm{C}}$ vs T' values published by a superconductor manufacturer [18]. Similarly, the resistivity of the copper also changes with temperature and was modelled according to Equation (3) [19].

$\rho_{\mathrm{cu}}=(0.0084 \mathrm{~T}-0.4603) \times 10^{-8}$

where, $\rho_{\mathrm{Cu}}$ was the "resistivity of copper stabilizer $(\Omega . \mathrm{m})$ ". $\rho_{\mathrm{Cu}}$ plays the key part during the fault/quench operation. In this paper, the thickness of the copper stabilizer was assumed to be of $50 \mu \mathrm{m}$. The lumped electrical model of the cable was built using the $\Pi$ configuration, with the inductance and capacitance values being $61.75(\mu \mathrm{H} / \mathrm{km})$ and $630.38(\mathrm{nF} / \mathrm{km})$ respectively using the equations (4) and (5). These values are observed to be in accordance with the values published by industry [20].

$C=\frac{2 \pi \epsilon_{o} \epsilon_{r}}{\ln (R / r)}$

$L=\frac{\mu_{0} \mu_{r}}{2 \pi} \ln \left(\frac{R}{r}\right)$

where, $\mathrm{R}$ and $\mathrm{r}$ being the shield and conduction layer radius, $\epsilon_{0}$ and $\epsilon_{0}$ are the relative permittivity of air and dielectric, $\mu_{0}$ and $\mu_{\mathrm{r}}$ are the relative permeability of air and dielectric. To simulate the thermal properties, the heat source was modelled using the current being propagated in both the copper stabilizer and HTS layer, according to Equation (6).

$P_{\text {diss }}(t)=\mathrm{i}_{\mathrm{cu}}(t)^{2} R_{\mathrm{cu}}(t)+i_{\mathrm{HTS}}(t)^{2} R_{\mathrm{HTS}}(t)$

The power dissipated from the conduction and shield layers was fed as a heat source to the thermal model, while the temperature of the $\mathrm{LN}_{2}$ was set at $70 \mathrm{~K}$, i.e. subcooled to improve HTS performance. The operating temperature of the LN2 was set as a dirichlet boundary condition, thus neglecting the thermal invasion from ambient atmospheric conditions. A 2D HTS cable model was built using COMSOL (a FEM model), to achieve the $\mathrm{AC}$ loss results, to be used inside the analytical model as shown in Fig. 3.

From the AC loss results as seen in Fig. 3, the time domain analytical AC loss equations for both conduction and shield

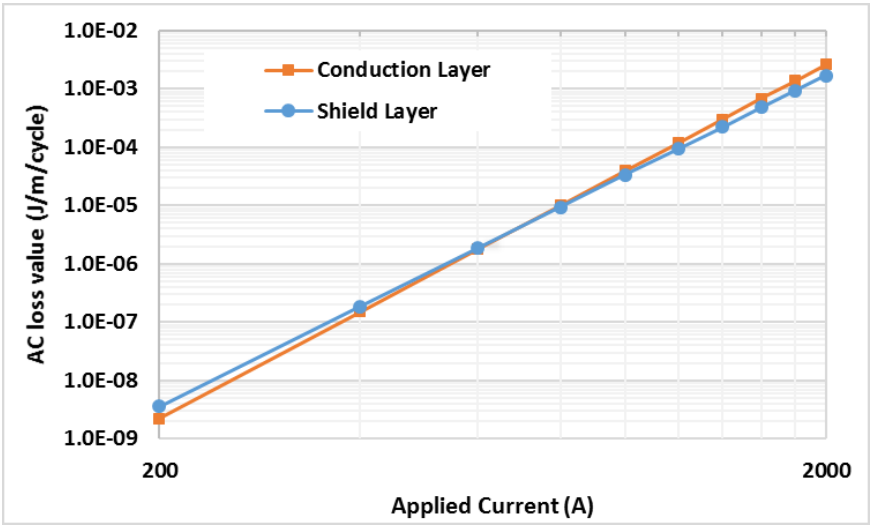

Fig. 3: AC loss results of the HTS DC cable, derived using Comsol. 
layer are derived as shown in Equation (7) and (8). The heat generated by the $\mathrm{AC}$ loss was provided as the heat input to the HTS thermal model in addition to the dissipated resistive power losses to evaluate the resultant temperature of the HTS layer for the immediate time step.

$q(\Delta t)=\frac{2}{3} \mu_{0} J_{C 1}^{2} p^{3}\left(k_{2}^{6.07}-k_{1}^{6.07}\right) \times \frac{l}{\Delta t} \times M . F$.

$q(\Delta t)=\frac{2}{3} \mu_{0} J_{c 1}^{2} p^{3}\left(k_{2}^{5.67}-k_{1}^{5.67}\right) \times \frac{l}{\Delta t} \times M . F$.

where, $\mathrm{q}(\Delta \mathrm{t})$ was the "heat transferred $(\mathrm{W})$ ", $\mathrm{J}_{\mathrm{C} 1}$ and $\mathrm{J}_{\mathrm{C} 2}$ being the "current densities" $(\mathrm{A} / \mathrm{m})$ of conduction and shield layer, $p$ is the "full penetration depth value $(\mathrm{m})$ ", $\mathrm{k}_{1}$ and $\mathrm{k}_{2}$ signifies the penetration depth factors (actual penetration/full penetration) for time steps $t_{1}$ and $t_{2}$ respectively, while $\Delta t$ equals $t_{2}-t_{1}, 1$ being the length $(\mathrm{m})$ of the HTS tapes and M.F. is a multiplication factor used to match the $\mathrm{AC}$ loss values derived from COMSOL as seen in Fig. 3.

The heat model has been modelled for the first time using the Simscape thermal components, which will significantly improve the accuracy of the results. The parameters of the heat model were observed to vary dynamically under cryogenic operating conditions [21]. Thus, thermal conductivity and specific heat are defined as variables, depending on the operating temperature. Considering a uniform heat flow in the radial direction through several layers of the HTS cable, the thermal conduction process along the solid layers was modelled by using the Equation (7).

$q(\Delta t)=A \times \lambda \times \frac{\Delta t}{\Delta x}$

where, A being the "cross-sectional area of the layer $\left(\mathrm{m}^{2}\right)$ ", $\Delta \mathrm{t}$ was the "difference in temperature across the layers $(\mathrm{K})$ ", $\Delta \mathrm{x}$ was the "thickness of the layer (m)" and $\lambda$ was the "thermal conductivity of the layer (W/(m.K))". Similarly, whenever a certain heat was applied, the layer absorbs it to a certain extent before transferring it to the next adjacent layer. This was defined as the thermal mass and was modelled as shown in the Equation (8).

$Q=m \times C_{p} \times \Delta t$

where, $\mathrm{m}$ was the "mass of the conduction layer $(\mathrm{kg})$ ", $\mathrm{Cp}$ was the "specific heat (W/(kg.K))". Similarly, the thermal conduction between the $\mathrm{LN}_{2}$ and the cryostat wall was modelled using

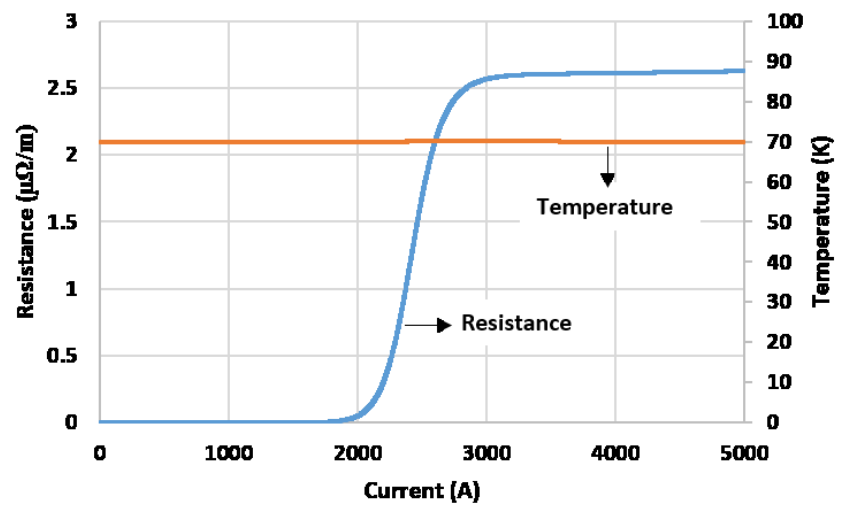

Fig. 4: Dynamic resistive properties of the HTS DC cable under ramping current application. a convective heat transfer equation, as shown in Equation (9).

$q(\Delta t)=A \times h \times \Delta t$

where, $\mathrm{h}$ was the "heat transfer coefficient of the $\mathrm{LN}_{2}$ medium $\left(\mathrm{W} /\left(\mathrm{m}^{2} . \mathrm{K}\right)\right)$ ". It has been found in the literature that the heat transfer coefficient of $\mathrm{LN}_{2}$ varies with operating temperature, which makes it very critical for quench modelling [20]. Thus, the heat transfer coefficient, ' $h$ ' of $\mathrm{LN}_{2}$ has been also modelled as a variable.

The steady state characteristics of the HTS DC cable model are derived by applying a ramping current of $1000 \mathrm{~A} / \mathrm{sec}$ to evaluate its dynamic resistive properties as seen in Fig. 4. The resistance of the HTS DC cable was observed to increase exponentially beyond the critical current until it matches the resistance of the copper former, beyond which the resistance of copper former increases gradually in accordance with temperature as shown in Equation (3). From Fig. 4, the change in temperature of the HTS layer was observed to be limited to only $0.1 \mathrm{~K}$, making it a fault current tolerant design, with minimum interruption to the network propulsion system.

\section{FAULT CURRENT ReSPONSE}

The generators $\left(G_{1}\right.$ and $\left.G_{2}\right)$, and HTS cables are rated for 8 $\mathrm{MW}$, while each of the propulsion motors $\left(\mathrm{M}_{1}, \mathrm{M}_{2}, \mathrm{M}_{3}\right.$ and $\mathrm{M}_{4}$ ) are rated for $2 \mathrm{MW}$ each for the redundant operation of the network during the failure of either one of the generators or cables. Thus, under stable conditions, two generators are set to propel two propulsion motors each independently, with the interconnecting switchgear in the off state. Hence, only half

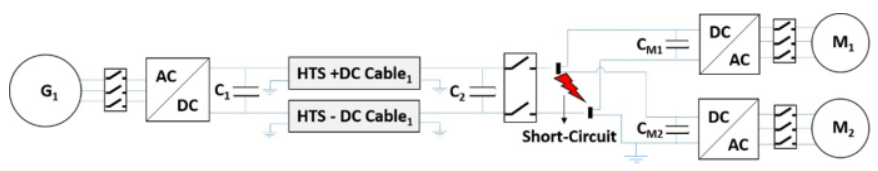

Fig. 5: Section of the DC architecture with fault location.

the circuit was modelled and represented in this current study as shown in Fig. 5.

Line to line fault in a DC network will result in a sudden capacitive discharge due to the fall in voltage, leading to a huge rise in fault current magnitude in a short time. The capacitance values used in the following study are as shown in Table I. Due to the high efficiency requirements of the electric aircraft, the capacitors need to have a very low internal resistance, which also aids in the increased fault current magnitude.

TABLE I

CAPACITANCE PARAMETERS

\begin{tabular}{ccl}
\hline \hline Capacitor & Value & Series Internal Resistance \\
\hline $\mathrm{C}_{1} \& \mathrm{C}_{2}$ & $3 \mathrm{mF}$ & $0.1 \mathrm{~m} \Omega$ \\
$\mathrm{C}_{\mathrm{M} 1} \& \mathrm{C}_{\mathrm{M} 2}$ & $1 \mathrm{mF}$ & $0.1 \mathrm{~m} \Omega$ \\
\hline
\end{tabular}

As shown in Fig. 5, a line to line short circuit fault was simulated with a short circuit resistance of $10 \mathrm{~m} \Omega$ for $10 \mathrm{~ms}$ 


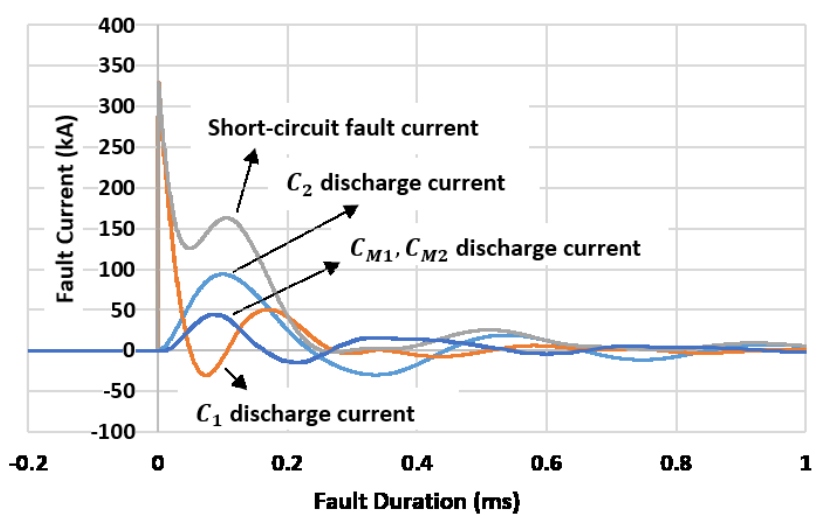

Fig. 6: Fault current decomposition of the DC line to line fault.

duration. The resultant fault current flowing through the short circuit path was as seen in Fig. 6, with the major components resulting in the large fault current magnitude. It was observed that, due to the location of the $\mathrm{C}_{2}$ next to the short circuit location, it resulted in a sharp rise time of the fault current and the large discharge current magnitude. This will result in a great challenge to the switching components to operate in such a small duration (i.e. $<10 \mu \mathrm{s})[23,24]$.

Two different approaches to limit the fault current magnitude were employed in this current study using superconducting components. First method employs SFCL and the second one uses FCL HTS DC cable, which are elaborated in the following sections.

\section{A. Using SFCL}

SFCL offers negligible resistance under normal conditions and operates as a fault current limiter by introducing large resistance instantaneously upon quenching [25]. The use of SFCL's to limit the surge currents in DC systems was already proved by integrating them in series to the DC links and battery banks $[26,27]$. From Fig. 6 , it was observed that the discharge currents from $\mathrm{C}_{1}$ and $\mathrm{C}_{2}$ are the major components of the fault current. Hence, to limit the large capacitive discharge and not to provide any loss during the normal operating condition, a resistive SFCL's (i.e. $\mathrm{S}_{1}$ and $\mathrm{S}_{2}$ ) are placed in series to the capacitors as seen in Fig. 7. The design parameters of the SFCL are as shown in Table II.

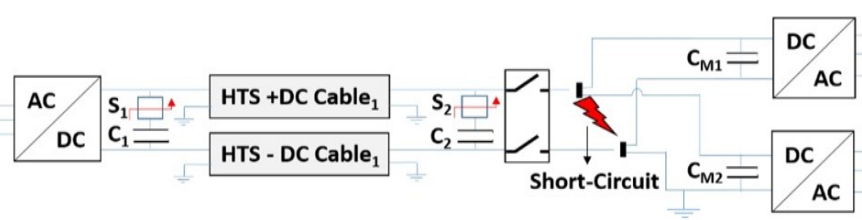

Fig. 7: Section of the DC architecture with SFCl's $\left(\mathrm{S}_{1}\right.$ and $\left.\mathrm{S}_{2}\right)$ located in series to $\mathrm{C}_{1}$ and $\mathrm{C}_{2}$ respectively.

TABLE II

SFCL DESIGN PARAMETERS

\begin{tabular}{cl}
\hline \hline \multicolumn{1}{c}{ Parameter } & \multicolumn{1}{c}{ Value } \\
\hline Rated voltage and current & $4 \mathrm{kV}$ and 2 kA \\
Length of HTS winding & $26.67 \mathrm{~m}(@ 1.5 \mathrm{~V} / \mathrm{cm})$ \\
Total length of HTS tape (Ic=100 A) used & $533.4 \mathrm{~m}$ \\
Thickness of copper stabilizer & $50 \mu \mathrm{m}$ \\
\hline
\end{tabular}

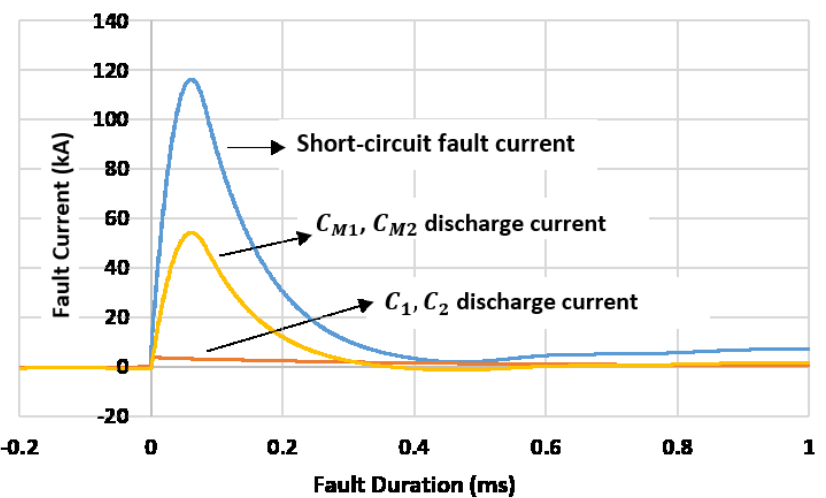

Fig. 8: Reduced fault current rating achieved using SFCL and its components resulting from various capacitance discharges.

From Fig. 8 it was observed that the fault current magnitude was reduced by nearly 3 times with significant improvement in the rise time due to the inductance offered by the propulsion motor cable links. The resultant fault current was due to the discharge current of the capacitors located next to the motor drive, which can even be regulated by adding the SFCLs in series. But addition of SFCL's at each capacitor will not result in addition of weight, but also results in additional AC losses emanating from high frequency charge/discharge cycles of the capacitor.

\section{B. Using FCL HTS DC Cable}

In a conventional network i.e. using copper cables, $\mathrm{C}_{2}$ serves the purpose of stabilizing the voltage drop occurring from the cable at the bus bar. However, HTS cables are known for their nearly zero resistance properties, resulting in no voltage drop across the cable length. Hence, $\mathrm{C}_{2}$ was removed and the value of $\mathrm{C}_{1}$ was doubled to compensate the loss of $\mathrm{C}_{2}$. Under steady state analysis, no change in the voltage profile at the bus bar was noticed. The fault current magnitude was observed to reduce by nearly $50 \%$ due to the dynamic resistance offered by the HTS cable.

As it was observed that the discharge path of the capacitor $\mathrm{C}_{1}$ includes HTS DC cable, the fault current component from $\mathrm{C}_{1}$ can be reduced by modifying the cable design with a fault current limiting HTS cable as shown in Fig. 9 (a). For this purpose, the copper former of the HTS cable was replaced by

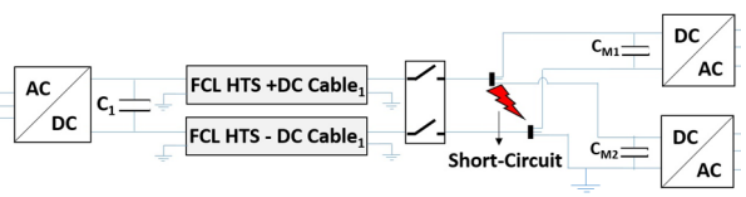

(a)

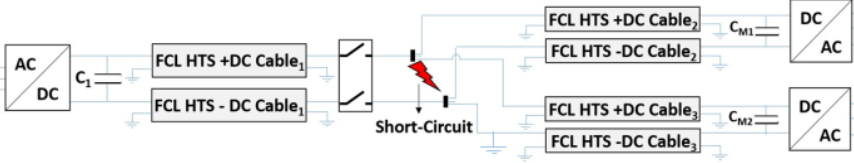

(b)

Fig. 9: Modified DC architecture $\left(C_{2}\right.$ removed and $\left.C_{1}=6 \mathrm{mF}\right)$ employing FCL HTS cables. 


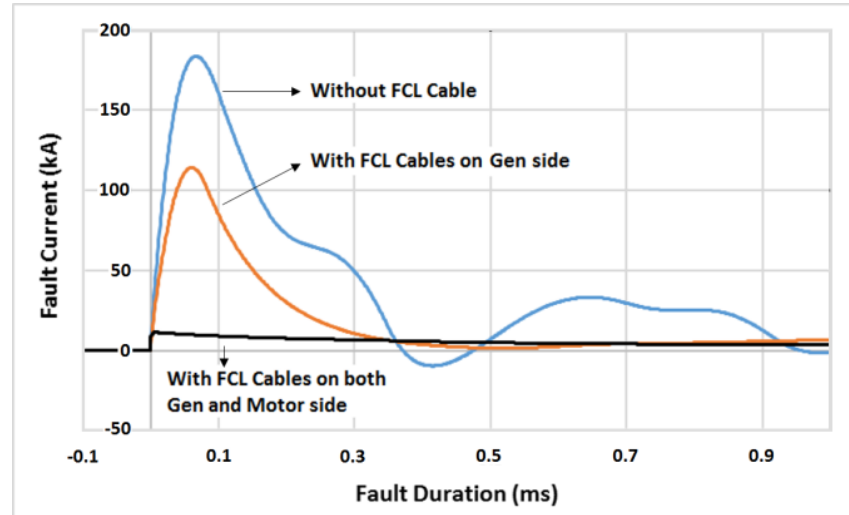

Fig. 10: Comparison of fault currents achieved with HTS cable and FCL HTS cable in the modified DC architecture (without $\mathrm{C}_{2}$ ).

a hollow stainless-steel former with the $\mathrm{LN}_{2}$ flowing through it, thus offering cooling from either side of the HTS layer. Use of FCL HTS cables for limiting the fault currents in the power system was well reported in the literature $[28,29]$.

Employing the FCL HTS cable, the resultant fault current was reduced to only $114 \mathrm{kA}$ as shown in Fig. 10, which was primarily due to the discharge currents emanating from capacitors on the motor drive end. Thus, to remove the residual fault current component also, the short length cable links provided on the motor drive end are replaced by FCL HTS cables as shown in Fig. 9 (b). The resultant fault current was observed to reduce to $11.4 \mathrm{kA}$, which was nearly just $4 \%$ of the principle fault current rating i.e. $330 \mathrm{kA}$. This fault current rating can be further reduced by reducing the thickness of copper stabilizer, which results much quicker quench of the FCL HTS cable. With reduced fault current rating, the fault clearance time has now been significantly, but still poses a challenge to operate within ms duration, to avoid any permanent damage to the FCL HTS cable from resultant temperature rise.

\section{CONCLUSIONS}

Line to line short circuit was the most critical fault in the DC network leading to the catastrophic failure of the entire system. With fault current magnitudes of more than $100 \mathrm{kA}$, it was very challenging to operate the switchgear and the resultant switchgear size will greatly impact the efficiency of the electric aircraft. In this paper, employing superconducting components, two different ways to limit the fault current magnitude have been achieved. The resultant fault current magnitude was reduced significantly up to $11.4 \mathrm{kA}$, reducing the rating of the switchgear required.

Similarly, a novel thermos-electric model of the HTS DC cable was presented with the simplified $\mathrm{AC}$ loss equations in time domain. This model was further modified to investigate the FCL HTS cable behavior, arriving at a significantly reduced fault current rating of the turbo-electric DC network. Upon fault occurrence, the FCL HTS cables needs to be taken off the power supply, for the cool down process, during which the redundant power supply from the other generator will be used. Further investigation is required to determine the operat- ing characteristics of the switchgear for the reliable operation of the turbo-electric propulsion system of the electric aircraft.

\section{REFERENCES}

[1] H. D. Kim, G. V. Brown, and J. L. Felder, "Distributed turboelectric propulsion for hybrid wing body aircraft," in Proc. 9th Int. Power. Lift Conf., London, U.K., pp. 092407 (25), Jul. 2008

[2] Flightpath 2050, "Europe's vision for aviation, European commission, publications office of the European union," 2011. [Online]. Available: https://ec.europa.eu/transport/sites/transport/files/modes/air/doc/flightpat h2050.pdf, Accessed on: Oct 18, 2018.

[3] "Electric Propulsion," in Commercial aircraft propulsion and energy systems research reducing global carbon emissions, Washington, DC, The National Academies Press, 2016.

[4] J. A. Rosero, J. A. Ortega, E. Aldabas and L. Romeral, "Moving towards a more electric aircraft," in IEEE Aerospace and Electronic Systems Magazine, vol. 22, no. 3, pp. 3-9, March 2007.

[5] B. Sarlioglu and C. T. Morris, "More Electric Aircraft: Review, Challenges, and Opportunities for Commercial Transport Aircraft," in IEEE Transactions on Transportation Electrification, vol. 1, no. 1, pp. 54-64, June 2015

[6] M. J. Armstrong, et al., "Architecture, Voltage and Components for a Turboelectric Distributed Propulsion Electric Grid," NASA CR-2015218440, July 2015

[7] F. Berg, J. Palmer, P. Miller and G. Dodds, "HTS System and Component Targets for a Distributed Aircraft Propulsion System," in IEEE Transactions on Applied Superconductivity, vol. 27, no. 4, pp. 1-7, June 2017.

[8] P. J. Masson, G. V. Brown, D. S. Soban and C. A. Luongo, "HTS machines as enabling technology for all-electric airborne vehicles," Superconductor Science and Technology, vol. 20, no. 8, pp. 748-756, 2017.

[9] C. E. Jones, P. J. Norman, S. J. Galloway, M. J. Armstrong and A. M. Bollman, "Comparison of Candidate Architectures for Future Distributed Propulsion Aircraft," IEEE Transactions on Applied Superconductivity, vol. 26, no. 6, pp. 1-9, Sept. 2016.

[10] NASA, "High-Voltage Power System for Hybrid Electric Aircraft Propulsion," National Aeronautics and Space Administration (NASA). [Online]. Available: https://technology.nasa.gov//t2media/tops/pdf/LE W-TOPS-104.pdf, Accessed on: Oct 18, 2018.

[11] T. J. McCoy, "Trends in ship electric propulsion," IEEE Power Engineering Society Summer Meeting, Chicago, IL, USA, vol.1, pp. 343-346, 2002.

[12] J. F. Hansen and F. Wendt, "History and State of the Art in Commercial Electric Ship Propulsion, Integrated Power Systems, and Future Trends," in Proceedings of the IEEE, vol. 103, no. 12, pp. 2229-2242, Dec. 2015.

[13] S. Nolan, C. E. Jones, P. J. Norman and S. J. Galloway, "Understanding the impact of failure modes of cables for the design of turbo-electric distributed propulsion electrical power systems," International Conference on Electrical Systems for Aircraft, Railway, Ship Propulsion and Road Vehicles \& International Transportation Electrification Conference (ESARS-ITEC), Toulouse, pp. 1-6, 2016.

[14] S. S. Fetisov, V. V. Zubko, S. Y. Zanegin, A. A. Nosov and V. S. Vysotsky, "Numerical Simulation and Cold Test of a Compact 2G HTS Power Cable," in IEEE Transactions on Applied Superconductivity, vol. 28, no. 4, pp. 1-5, June 2018

[15] Z. Zhu, Y. Wang, S. Venuturumilli, J. Sheng, M. Zhang and W. Yuan, "Influence of Harmonic Current on Magnetization Loss of a Triaxial CORC REBCO Cable for Hybrid Electric Aircraft," in IEEE Transactions on Applied Superconductivity, vol. 28, no. 4, pp. 1-5, June 2018

[16] K. Satpathi, A. Ukil and J. Pou, "Short-Circuit Fault Management in DC Electric Ship Propulsion System: Protection Requirements, Review of Existing Technologies and Future Research Trends," IEEE Transactions on Transportation Electrification, vol. 4, no. 1, pp. 272-291, 2018.

[17] A. Morandi, "HTS dc transmission and distribution: concepts, applications and benefits," Superconductor Science and Technology, vol. 28, no. 12, pp. 123001 (16), 2015.

[18] SuperOx, "2G HTS wire properties," 2016. [Online] Available: http://www.superox.ru/products/0003.xls, Accessed on: Jan 12019.

[19] J. E. Campbell, E. A. Eldridge and J. K. Thompson, 'Handbook on Materials for Superconducting Machinery,' Metals and Ceramics Information Center, Battelle, pp: 1-1330, 1970. 
[20] Nexans, "Superconductivity white paper," 2006. [Online] Available: https://www.nexans.co.uk/UK/2011/Superconductivity\%20White\%20Pa per_1.pdf, Accessed on Oct 182018.

[21] M. Zhang, K. Matsuda, and T. A. Coombs, "New application of temperature-dependent modelling of high temperature superconductors: Quench propagation and pulse magnetization," Journal of Applied Physics, vol. 112, no. 4, pp. 043912 (1-8), 2012.

[22] T. Jin, J. Hong, H. Zheng, K. Tang and Z. Gan, "Measurement of boiling heat transfer coefficient in liquid nitrogen bath by inverse heat conduction method," J. Zhejiang Univ. Sci. A, vol. 10, n0. 5, pp. 691-696, 2009.

[23] X. Pei, O. Cwikowski, D. S. Vilchis-Rodriguez, M. Barnes, A. C. Smith and R. Shuttleworth, "A review of technologies for MVDC circuit breakers," IECON 2016 - 42nd Annual Conference of the IEEE Industrial Electronics Society, Florence, pp. 3799-3805, 2016.

[24] W. Holaus and K. Frohlich, "Ultra-fast switches- a new element for medium voltage fault current limiting switchgear," IEEE Power Engineering Society Winter Meeting. Conference Proceedings (Cat. No.02CH37309), New York, NY, USA, vol.1, pp. 299-304, 2002.

[25] H. S. Ruiz, X. Zhang and T. A. Coombs, "Resistive-Type Superconducting Fault Current Limiters: Concepts, Materials, and Numerical Modeling," in IEEE Transactions on Applied Superconductivity, vol. 25, no. 3, pp. 1-5, June 2015.

[26] L. Chen, H. Chen, Z. Shu, G. Zhang, T. Xia and L. Ren, "Comparison of inductive and resistive SFCL to robustness improvement of a VSCHVDC system with wind plants against DC fault," IEEE Transactions on Applied Superconductivity, vol. 26, no. 7, pp. 1-8, Oct. 2016.

[27] D. M. Yehia and D. A. Mansour, "Modeling and Analysis of Superconducting Fault Current Limiter for System Integration of Battery Banks," IEEE Transactions on Applied Superconductivity, vol. 28, no. 4, pp. 1-6, June 2018.

[28] H. Kojima, F. Kato, N. Hayakawa, M. Hanai and H. Okubo, "Feasibility Study on a High-Temperature Superconducting Fault-Current-Limiting Cable (SFCLC) Using Flux-Flow Resistance," in IEEE Transactions on Applied Superconductivity, vol. 22, no. 2, pp. 4800105-4800105, April 2012.

[29] H. J. Kim, J. W. Shim, K. Sim and K. Hur, "Assessment of Improved Power Quality Due to Fault Current Limiting HTS Cable," in IEEE Transactions on Applied Superconductivity, vol. 23, no. 3, pp. 56021045602104, June 2013 